\title{
Nicanor Parra (1914-2018)
}

\section{Jorge Monteleone}

El iconoclasta, el sedicioso, el libertador, el antipoeta Nicanor Parra es uno de los más grandes poetas hispanoamericanos, pero esa grandeza está en las antípodas de la altisonancia: su poesía es inmediata, inventiva, inesperada. Tiene la fuerza de la consigna, la extrañeza de un artefacto vanguardista, la banalidad iconoclasta de una broma, todo dicho en el ritmo del habla de la gente pero dinamitando siempre la opinión generalizada, los lugares comunes, las sacristías de la Razón occidental. La poesía como un acto de sedición. Parra obró en el ridículo y el absurdo y abrió en su encono centrífugo el horizonte de la vitalidad, como si fuera un nihilista festivo, un sarcástico laudatorio, el que celebra la risa en las barbas de la muerte: "Parra se ríe como condenado/ ¡cuando no se rieron los poetas!/ a lo menos declara que se ríe// pasan los años pasan/ los años/ a lo menos parece que pasaran/ hipótesis non fingo/ todo sucede como si pasaran// ahora se pone a llorar/ olvidando que es antipoeta".

Esa fue su revolución permanente: la antipoesía.

La definición es temprana: "Qué es un antipoeta: / Un comerciante en urnas y ataúdes? / Un sacerdote que no cree en nada? / Un general que duda de sí mismo? / Un vagabundo que se ríe de todo / hasta de la vejez y de la muerte? / Un interlocutor de mal carácter? / Un bailarín al borde del abismo? / Un narciso que ama a todo el mundo? / Un bromista sangriento / deliberadamente miserable? / Un poeta que duerme en una silla? / Un alquimista de los tiempos modernos? / Un revolucionario de bolsillo? / Un pequeño burgués? / Un charlatán? / Un dios? / Un inocente? / Un aldeano de Santiago de Chile? / Subraye la frase que considere correcta".

Nicanor Parra es uno de los más grandes poetas hispanoamericanos, pero esa grandeza está en las antípodas de la altisonancia: su poesía es inmediata, inventiva, inesperada. Tuvo la fuerza de la consigna, la extrañeza de un artefacto vanguardista, la banalidad iconoclasta de una broma, todo dicho en el ritmo del habla de la gente pero dinamitando siempre la opinión generalizada, los lugares comunes, las sacristías de la razón occidental. La poesía como un acto de sedición. Parra obró en el ridículo y el absurdo y abrió en su encono centrífugo el horizonte de la vitalidad, como si fuera un nihilista festivo, un sarcástico laudatorio, el que celebra la risa en las barbas de la muerte: "Parra se ríe como condenado/ ¡cuando no se rieron los poetas!/ a lo menos declara que se ríe// pasan los años pasan/ los años/ a lo menos parece que pasaran/ hipótesis non fingo/ todo sucede como si pasaran// ahora se pone a llorar/ olvidando que es antipoeta". 
Ésa fue su revolución permanente: la antipoesía. Surgió con su segundo libro, publicado en 1954: Poemas y antipoemas. A lo cual siguieron varios volúmenes que profundizaron su poética: La cueca larga (1958), Versos de salón (1962), Canciones rusas (1967), La camisa de fuerza (1969) reunidos luego en Obra gruesa (1969). Descendiente natural de Vicente Huidobro y de su enorme Altazor ("Qué sería de Chile sin Huidobro / Qué sería de la poesía chilena sin este duende", escribió) que siempre opuso a la huella monumental de Neruda y asumido discípulo de Macedonio Fernández y su humorismo de la nada, Nicanor Parra destronó para siempre al yo trascendente y su sentimentalismo egotista, para suplantar a la figura del agonista lírico, del poeta vate o el vidente, por un hombre común: "Los poetas bajaron del Olimpo. [?]/ Nosotros sostenemos/ que el poeta no es un alquimista/ el poeta es un hombre como todos/ un albañil que construye su muro:/ un constructor de puertas y ventanas.// Nosotros conversamos/ en el lenguaje de todos los días/no creemos en signos cabalísticos". Es decir, un individuo que transforma también en su caricatura: el "energúmeno". A pesar de su cotidianidad, esta figura no es un sujeto reconocible en la biografía o la experiencia: se trata de un remedo burlón del yo romántico y luego del sujeto lírico del modernismo, que parodia al convertirlo en el pequeño ego de una especie de sujeto kafkiano atravesado por la risa.

Otro rasgo de la antipoesía es la busca del habla cotidiana hasta hacer estallar todos los presupuestos, como si el poeta pudiera transformar la lengua misma y su capacidad de nominación o, mejor dicho, pudiera denunciar la arbitrariedad del nombre y asumir la capacidad creadora de la poesía para mutar los hábitos perceptivos, la experiencia misma de lo real: "A los amantes de las bellas letras/ hago llegar mis mejores deseos/ voy a cambiar de nombre algunas cosas.// Mi posición es ésta:/ el poeta no cumple su palabra/ si no cambia los nombres de las cosas./ [...]./ ¿Mis zapatos parecen ataúdes?/ Sepan que desde hoy en adelante/ los zapatos se llaman ataúdes./ Comuníquese, anótese y publíquese/ que los zapatos han cambiado de nombre:/ desde ahora se llaman ataúdes".

Pero si bien la antipoesía juega con las arbitrariedades del sentido del lenguaje, a la vez cultiva las certezas de los ritmos del habla. Sobre eso Nicanor Parra siempre tuvo una sensibilidad alerta y una frescura de canción (en su familia abundan los folkloristas, como su hermana, la gran Violeta Parra, con la que tuvo un vínculo profundo y a la que le enseñó también cuestiones de versificación). La antipoesía está viva porque vive en ella "la sustancia lingüística de las diferentes comunidades a lo largo de la historia". Parra incluso teorizaba acerca de la relación entre la métrica castellana y el habla de la comunidad. Sostenía que el verso de once sílabas, el endecasílabo, era la síntesis rítmica que constituye la columna vertebral del español y que se manifiesta en la oralidad. Al borrar los aspectos retóricos que ofrecía la estructura del endecasílabo clásico, Parra trabajó en lo que él llamaba un "endecasílabo oral". De allí que considerara el ritmo de la métrica íntimamente ligado al habla común del español un resultado del verso. En conversación con Leónidas Morales T., dijo: “El octosílabo predominó en una época. Predominó hasta el momento en que se hizo la síntesis. Porque en una época estaba por una parte el octosílabo, como el mester de juglaría, y por otra parte el mester de clerecía, que era el de catorce sílabas. Ya está. Se produce la síntesis. Ocho más catorce, igual veintidós. Partido por dos, igual once. Síntesis, medio aritmético, que pasa a ser el metro no tan sólo de la poesía, sino del habla española. [...] Estos no son ni juglares ni clérigos sino que es el común de los mortales ya. Una especie de nueva clase sociocultural. [...]. Nosotros venimos de la oralidad, no vamos a construir un mundo aparte".

Otro rasgo de la antipoesía es su carácter indeterminado y contradictorio: poesía que no fusiona los contrarios sino los mantiene en movimiento. Parra fue profesor de matemáticas y de física y afirmó a menudo que le interesaban el principio de indeterminación 
y el principio de relatividad como condiciones propias de la antipoesía. Pero también lo definió su descubrimiento del Tao Te Ching, de Lao Tsé, al que alude varias veces como una especie de modelo de esa tensión de contrarios que no se subsumen entre sí. Como señaló su gran heredero poético, el poeta chileno Enrique Lihn, "al hablar del Tao, Parra diseña el modelo de lo que llama su antipoesía". Lihn cuenta al respecto una hermosa anécdota ocurrida en 1985, al salir de la presentación de Hojas de Parra, cuando el poeta le confesaba: "Antes de leer el Tao Te Ching yo era una especie de hoja en la tormenta; debo haber sido un iniciado porque, leyéndolo comprendí mis propios poemas. Fijate tú lo que dice el sujeto que habla en ese libro: 'No hay nada superior a la virtud en el mundo'. Bueno, eso no tiene nada de especial. Pero, atención que viene lo siguiente. Punto dos: 'Rehúye la virtud porque ella te puede conducir al abismo'. Y ahí te deja el libro. Plantea las contradicciones sin resolverlas, nada de síntesis: tesis y antítesis. Tú lees eso y sientes que te están hablando de algo real. El hablante lírico, digamos, no se deja nunca atrapar. Es imprescindible no fallar. A lo mejor, pensar para contradecir es negarse a entender. Te instalas en una doctrina y todo lo que no hace sistema con ella, deja sencillamente de existir o en la práctica hay que eliminarlo".

De este cauce poderoso partieron los libros siguientes de Nicanor Parra. Por ejemplo los dos volúmenes de Sermones y prédicas del Cristo de Elqui (1977 y 1979). Como si tomara en solfa el propio sujeto antinómico de los antipoemas, ahora la voz poética se transforma en la de un predicador popular al modo de una mascarada. Se torna uno de esos sermoneadores callejeros que asumen su santidad en las plazas públicas. Con el propio dinamismo de la contradicción, al artero yo de los antipoemas, Parra le crea otro antagonista: el hablador loco e ingenuo y que anda en toga y publica folletos de redención. Se inspiró en un personaje real que conoció en los años treinta y se llamaba Domingo Zárate Vega, "un cura francotirador de una iglesia inexistente, que al mismo tiempo es Cristo y no es la iglesia oficial". Afirmativo y con el autoritarismo de los consejos maternos, de los maestros de escuela, de los oradores de barricada, el Cristo de Elqui demuestra que es imposible predicar y que todo énfasis totalizador se vuelve ridículo: "Toda prédica cae en el Cristo de Elqui -dice Parra- y ahí se vienen abajo los discursos ideológicos, políticos o religiosos". Parra todo lo relativiza y allí ejercita de nuevo una anárquica libertad. "El escritor es una república independiente", escribió. Otra vez la indeterminación y la relatividad como política poética. Hojas de Parra (1985) reúne poemas escritos entre 1969 y 1985 y allí el antipoeta y el predicador se unen en una especie de sujeto que caricaturiza el nombre mismo del poeta. "Habla Parra", como un ventrílocuo de sí mismo y explota la forma del poema bajo los discursos circulantes, desde la mera noticia hasta la pancarta, desde el monólogo dramático hasta la copla, como forma de intervención pública. En pleno régimen de Pinochet, escribe, por ejemplo: "17 ELEMENTOS SUBVERSIVOS/ fueron sorprendidos ayer/ en los alrededores de La Moneda/transportando naranjas/y un ejemplar de la Sagrada Biblia// 3 de ellos se dieron a la fuga/ no sin antes batirse con la policía/ que se vio obligada a actuar en defensa propia //los delincuentes resultaron muertos". O bien: "CHILE fue primero un país de gramáticos/ un país de historiadores/ un país de poetas/ ahora es un país de? puntos suspensivos".

Precursor del pop y de la poesía coloquialista, adelantado de la poesía política y del humorismo en poesía, gran referente de la poesía de los años sesenta, moderno irredento, Parra también revolucionó la forma misma del poema profundizando tanto la exploración de lo tipográfico como su dimensión espacial. Como si fuera un trapero del mundo del signo o un semiólogo de los restos, el antipoeta no sólo es el que oye e imita las múltiples voces colectivas, sino también aquel que lee y reproduce todas las formas en las que el mundo social se autodesigna: letreros, grafitis, frases hechas, opiniones, noticias, nombres, fórmulas. En eso consiste la serie que llamó Artefactos (1972) y en una dirección similar los Trabajos prácticos (1996) y los Artefactos visuales 
(2001). Allí una imagen cualquiera o una fotografía se combina con una inscripción para generar un efecto de concentrada incongruencia, un sarcasmo, una paradoja o un chiste. La imagen toma aquí el lugar del espacio cultural o cotidiano que la leyenda altera: la foto de un tomate atravesado por un clavo es una "naturaleza muerta"; un huevo en equilibrio vertical sobre una superficie especular oscura es el "Descubrimiento de América", la desmañada caligrafía del poeta en letras mayúsculas con un recuadro que dice: "El pensamiento muere en la boca". Como el arte recién hecho del ready made, los artefactos de Parra combinan la aparición de un objeto o un resto como arrancado a la vida cotidiana y sometido a la antipoesía. Una experiencia singular en la poesía hispanoamericana, que podría compararse, como una verdadera descendencia creativa de los Artefactos de Parra, con los notables Poemas plagiados, del poeta argentino Esteban Peicovich, que murió también en 2018. Ambos destronan con cada uno de sus experimentos la persona del poeta y lo transforman, cada uno a su modo particular, en bricoleur, es decir, conforman el poema a partir de materiales heterogéneos que se hallan disponibles, a mano, y que reciclan en una nueva estructura, que es también una respuesta poética a lo real. Y siguieron otros libros, como los publicados en el 2006: Obras completas er algo +, Obras públicas o Discursos de sobremesa, en el cual se transcriben las series de poemas con los cuales Parra pronunció diversos discursos, por ejemplo el elogio de Juan Rulfo en "Mai Mai Peñi" al inaugurar la Feria del Libro de Guadalajara en 1991 o la celebración de Vicente Huidobro en "Also sprach Altazor" en el centenario de su nacimiento, 1993). Un continuo irreverente: "La poesía pasa - la antipoesía también / el poeta nos habla a todos / sin hacer diferencia de nada".

Con él murió por error a los 103 años el último poeta inmortal. Su última broma fue que lo velaran en la Catedral de Santiago, a él, que escribió: "ustedes están asistiendo a los funerales del yo poético / que reventó por exceso de delicadeza // a depositar una corona de rosas / en la tumba del poeta desconocido".

Por eso esto no es un homenaje: es una desmentida contra la muerte. 